\title{
Alterations in Gene Expression of Renin-Angiotensin System Components and Related Proteins in Colorectal Cancer
}

\author{
Danial Mehranfard (D, ${ }^{1}$ Gabriela Perez, ${ }^{2}$ Andres Rodriguez, ${ }^{3}$ Julia M. Ladna, ${ }^{4}$ \\ Christopher T. Neagra, ${ }^{5}$ Benjamin Goldstein, ${ }^{6}$ Timothy Carroll, ${ }^{7}$ Alice Tran, ${ }^{8}$ Malav Trivedi, ${ }^{1}$ \\ and Robert C. Speth ${ }^{1}$
}

${ }^{1}$ College of Pharmacy, Nova Southeastern University, Fort Lauderdale, FL, USA

${ }^{2}$ Department of Internal Medicine, Palmetto General Hospital, Hialeah, FL, USA

${ }^{3}$ Department of Internal Medicine, University of Miami/Jackson Memorial Hospital, Miami, FL, USA

${ }^{4}$ Broward Health Medical Center, Fort Lauderdale, FL, USA

${ }^{5}$ Baylor College of Medicine, Houston, TX, USA

${ }^{6}$ University of Florida, Gainesville, FL, USA

${ }^{7}$ College of Psychology, Nova Southeastern University, Fort Lauderdale, FL, USA

${ }^{8}$ Halmos College of Arts and Sciences, Nova Southeastern University, Fort Lauderdale, FL, USA

Correspondence should be addressed to Robert C. Speth; rs1251@nova.edu

Received 2 February 2021; Revised 13 May 2021; Accepted 7 June 2021; Published 6 July 2021

Academic Editor: Peter Sever

Copyright (c) 2021 Danial Mehranfard et al. This is an open access article distributed under the Creative Commons Attribution License, which permits unrestricted use, distribution, and reproduction in any medium, provided the original work is properly cited.

\begin{abstract}
Hypothesis/Introduction. Recent studies suggest involvement of the renin-angiotensin system (RAS) in cancers, including colorectal cancer (CRC). This study focuses on the association of genes encoding 17 proteins related to the RAS within a Japanese male CRC population. Materials and Methods. Quantitative expression of the RNA of these 17 genes in normal and cancerous tissues obtained using chip arrays from the public functional genomics data repository, Gene Expression Omnibus (GEO) application, was compared statistically. Results. Expression of four genes, AGT (angiotensinogen), ENPEP (aminopeptidase A) MME (neprilysin), and PREP (prolyl endopeptidase), was significantly upregulated in CRC specimens. Expression of REN (renin), THOP (thimet oligopeptidase), NLN (neurolysin), PRCP (prolyl carboxypeptidase), ANPEP (aminopeptidase N), and MAS1 (Mas receptor) was downregulated in CRC specimens. Conclusions. Presuming gene expression parallel protein expression, these results suggest that increased production of the angiotensinogen precursor of angiotensin (ANG) peptides, with the reduction of the enzymes that metabolize it to ANG II, can lead to accumulation of angiotensinogen in CRC tissues. Downregulation of THOP, NLN, PRCP, and MAS1 gene expression, whose proteins contribute to the ACE2/ANG 1-7/Mas axis, suggests that reduced activity of this RAS branch could be permissive for oncogenicity. Components of the RAS may be potential therapeutic targets for treatment of CRC.
\end{abstract}

\section{Introduction}

1.1. Colorectal Cancer. Colorectal cancer is the second leading cause of cancer-related deaths in the USA and it is the third most common cancer in males and in females [1]. Globally, it is the second leading cause of cancer in females and third leading cause in males, with over half of the cases occurring in developed regions [2]. While there has been a large focus on CRC prevention by screening modalities, much remains undiscovered regarding better treatment options for this often-fatal disease. The current gold standard modality for diagnostic screening and early intervention is colonoscopy. With colonoscopies, physicians can directly visualize, locate, biopsy, and resect areas of concern. The incidence for CRC has decreased by $6.24 \%$ between 2005 and 2017 in both genders, across all ages and ethnicities [3]. However, the prevalence of the disease remains high. Due to socioeconomic factors such as barriers to initial screening 
and access to follow-up care, CRC contributes to a lethal diagnosis in $\sim 20 \%$ of newly diagnosed colon cancers, as many have already metastasized at initial presentation [4]. The use of lower-cost screening methods, such as fecal immunochemical tests (FIT) [5] or epigenetic changes and fecal hemoglobin, e.g., Cologuard ${ }^{\circledR}$, while not as accurate as colonoscopy, is an option that is FDA approved [6]. Many CRC patients also have genetic predispositions and increased lifestyle risk factors for CRC including alcohol and tobacco use, lack of physical activity, and obesity [4]. Current treatment options vary depending on the stage of the disease. CRC lesions are staged using TNM (primary tumor (T), regional lymph node involvement $(\mathrm{N})$, and distant metastasis (M)) staging of the combined American Joint Committee on Cancer (AJCC)/Union for International Cancer Control (UICC) [7]. According to the National Comprehensive Cancer Network guidelines (http://NCCN.org), treatment will depend on the stage and location of the disease as well as in-patient factors. Generally, for localized colon cancer, the curative treatment is surgical resection in surgical candidates. Nonsurgical options are available for patients with more advanced cancer. For patients with cancer that has metastasized, the therapy is surgery and/or adjunctive chemotherapy and radiation, depending on the stage of the disease. The current treatment options are invasive, and patients experience adverse side effects such as pain, disruption of their alimentary system, the need for colostomy bags, and systemic side effects of chemotherapy and radiation. Our study findings imply that already-existing, noninvasive, and well-tolerated therapies may be of benefit for the prevention and adjunctive treatment of CRC.

1.1.1. Pathophysiology of Colorectal Cancer. As reviewed by Cappell [8], the pathophysiology of CRC is well established. It can arise from a variety of mechanisms including sporadic mutation and familial syndromes or originate from a serrated hyperplastic polyp or adenomatous polyp (AP) through the adenoma-carcinoma sequence. The National Cancer Institute's (NCI's) Physician's Data Query (PDQ) cancer information summary about CRC states that the majority of colon cancers today arise from an AP through the adenoma to carcinoma sequence, although serrated-type hyperplastic polyps can also transform into CRC via a BRAF (B-Raf proto-oncogene serine/threonine kinase) mutation [9]. Molecular transformations such as those seen in epigenetic alterations, e.g., DNA methylation defects and microRNA instability, which can be affected by lifestyle and environmental factors, play a role in the development and pathogenesis of CRC as well [10]. Physicians routinely screen for the presence of APs with colonoscopy and the lesions are easily biopsied during the procedure for histological evaluation. Histological evaluation is imperative to determine the malignant potential of the cells [8]. Once a lesion is biopsied and evaluated histologically, the sample is classified. Adenomatous polyps can be classified as tubular, villous, or tubulovillous, with the villous subtype having a high risk for transformation to cancer [11].

Syndromes that place patients at high risk for CRC include familial adenomatous polyposis (FAP), the result of an autosomal dominant (AD) germline mutation of the APC (adenomatous polyposis coli) gene on chromosome $5 \mathrm{q}$, and hereditary nonpolyposis colon cancer (HPNCC) that is a result of mutated mismatch repair genes; see reviews [12, 13]. Patients with FAP will inevitably develop CRC via the growth of hundreds of colonic adenomas after puberty, and they require colectomy at a young age to prevent the inevitable development of CRC. Patients with HNPCC will not have the growth of hundreds of polyps typically seen in FAP patients; however, they will have growth of several, usually right-sided, sessile polyps during their middle-aged years. This, with the use of Amsterdam II diagnostic criteria [8], enables practitioners to establish a clinical diagnosis of HNPCC.

Syndromic CRCs have allowed for the study and understanding of sporadic CRCs. We now understand that colon cancer is the result of a cascade of mutations that eventually lead to accelerated colonic cell multiplication, such as the mutations that occur in familial syndromes. In sporadic $\mathrm{CRC}$, mutations of genes including the APC regulatory gene, $\mathrm{k}$-ras cell-signaling gene, P53 or DCC tumor suppressor genes, or the mutation of mismatch repair genes may spontaneously occur and lead to CRC in patients without a germline mutation. Environmental factors also play a role in the evolution of sporadic CRC via the DNA methylation process that can lead to the inactivation of tumor suppressor genes by hypermethylation of the $\mathrm{CpG}$ islands in their promoter regions [14].

1.2. Renin-Angiotensin System. Several studies describe the possible involvement of the RAS in the pathophysiology of CRC [15-18]. While the RAS is primarily associated with the regulation of the cardiovascular system as well as fluid and electrolyte balance, we now know it to be involved in a wide range of cellular processes [19-21]. The modern-day RAS as shown in Figure 1 is a complexly organized system with many divergent pathways. Indeed, some of the enzymatic pathways of the RAS intersect with other metabolic pathways, e.g., ACE is also kininase II which metabolizes bradykinin and several other peptides; neprilysin, which forms Ang 1-7 from Ang I, also degrades atrial natriuretic peptide and several other peptides; neurolysin, which metabolizes Ang I to Ang 1-7 and Ang II at the Tyr-Ile bond, metabolizes neurotensin and other peptides. The signaling pathways of the RAS through its receptors, $\mathrm{AT}_{1}, \mathrm{AT}_{2}, \mathrm{AT}_{4}, \mathrm{Mas}$, and MrgD, are also complex and divergent, involving $G$ protein-activated enzymatic pathways, beta-arrestinactivated pathways, transactivation of EGF, and activation of NADPH oxidase, as reviewed [22-25]. Dysregulation of the RAS has been implicated in several cancers, including CRC, lung cancer, and gliomas [26-29].

\subsection{Constituents of the "Classical" and "Neoclassical" Renin- Angiotensin System}

1.3.1. Angiotensinogen (AGT) and Renin (Classical): AGT and REN. Angiotensinogen is an essential component of the RAS. It is the sole precursor of all of the angiotensin peptides, which play a critical role in the regulation of blood 


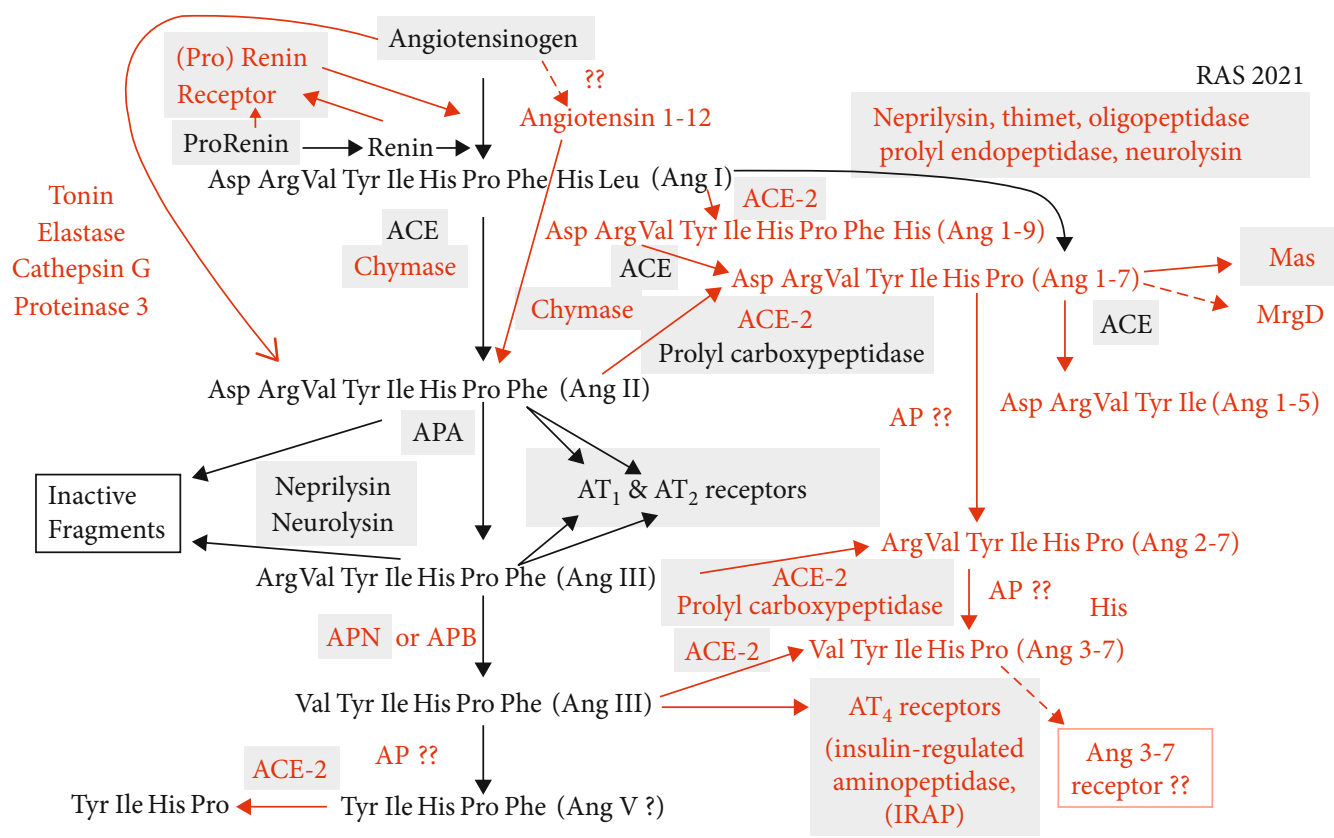

FIGURE 1: Current understanding of the renin-angiotensin system 2021. Black font indicates the classical RAS circa 1990. Red font indicates additional metabolic and signaling pathways that have been incorporated into the RAS since 1990. Proteins, enzymes, and receptors indicated in gray boxes are the proteins whose genes were evaluated in this analysis. Dotted lines indicate hypothetical pathways. ?? Uncharacterized enzymatic mediators.

pressure as well as fluid and electrolyte balance, primarily through the actions of angiotensin II (Ang II) acting on the $\mathrm{AT}_{1}$ Ang II receptor subtype (AT1R) [30]. Human AGT is primarily, but not exclusively, synthesized in the liver and constitutively secreted into the bloodstream. It has 485 amino acids, including a 33-amino acid signal peptide that is cleaved prior to circulation in the bloodstream. Circulating AGT is cleaved by renin to produce angiotensin I (Ang I), a 10-amino acid peptide cleaved from the $\mathrm{N}$ terminus of this protein. Renin is an aspartyl protease that is synthesized predominantly in the juxtaglomerular apparatus of the kidney and secreted into the circulation as the mature enzyme. The precursor protein (prorenin) is secreted from several tissues other than the juxtaglomerular apparatus including the adrenal gland, ovary, testis, placenta, retina, brain $[31,32]$, and collecting duct [33]. Renin is responsible for the cleavage of angiotensinogen to form Ang I. Prorenin (see also the next section), when bound to the prorenin receptor prorenin, can also form Ang I from angiotensinogen [34].

1.3.2. Prorenin Receptor (Neoclassical): ATP6AP2. Prorenin is the precursor of renin. It exists in circulating blood at concentrations that are 5 to 10 times higher than those of renin [35]. Previously, prorenin was considered to be an inactive form of renin with no physiological role. However, it has been known for some time that circulating levels of prorenin are elevated in diabetic subjects [36]. We now know that the prorenin receptor binds prorenin, uncovering the active site of the enzyme, as well as renin, subsequently enabling prorenin to cleave Ang I from angiotensinogen [34]. When prorenin and renin bind to the prorenin receptor, they also activate a protein kinase cascade response [34]. In addition to activating prorenin and generating an intracellular response [34], the prorenin receptor is also an accessory protein component of the V-ATPase proton pump ATPase 6 and a component of the Wnt signaling pathways; see review [37].

\subsubsection{Angiotensin-Converting Enzyme (ACE) (Classical):} $A C E$. Ang I is converted to Ang II, the primary hormone of the RAS, predominantly by ACE, a di-peptidyl carboxypeptidase also known as kininase II based upon its ability to metabolize bradykinin. It also metabolizes other peptides, notably substance $\mathrm{P}$ and enkephalins [38].

1.3.4. Chymase (Neoclassical): CMA1. Chymase is a serine protease that cleaves Ang I at the same site as ACE. Due to a high affinity for angiotensin I, chymase converts Ang I to Ang II at a substantially greater rate than does ACE [39]. Chymase is expressed in mast cells and is thought to also function in the degradation of the extracellular matrix and the regulation of submucosal gland secretion, as well as to oppose inflammation by inactivating allergens and neuropeptides causing inflammation [40]. While chymase has yet to be implicated in any cancers, it has been shown that chymase expression is upregulated in the human diabetic kidney, specifically in mesangial cells and vascular smooth muscle cells [41, 42] and in polycystic kidney disease [41].

\subsubsection{Angiotensin-Converting Enzyme-2 (ACE2)} (Neoclassical): ACE2. ACE2, while having a high homology to ACE, is a monocarboxypeptidase and has an entirely different spectrum of activity. It is primarily known for its 
ability to convert Ang II to angiotensin 1-7; although, it can also convert Ang I to angiotensin 1-9 [43, 44]. While unrelated to its functionality in the RAS, ACE2 is also notable for its role as the primary receptor for SARS and SARSCoV-2 coronaviruses $[45,46]$.

1.3.6. Prolylcarboxypeptidase (Angiotensinase C) (Classical): $P R C P$. Prolylcarboxypeptidase is one of several enzymes capable of cleaving a post proline amino acid. It was previously known as angiotensinase $\mathrm{C}$ based upon its ability to efficiently cleave the carboxy-terminal phenylalanine from Ang II [47].

1.3.7. $A T_{1}$ Receptor, Ang II Receptor Subtype (Classical): AGTR1. The $\mathrm{AT}_{1}$ receptor is the primary mediator of Ang II. It causes vasoconstriction, sodium retention, thirst, salt appetite, and aldosterone synthesis and release. It has a variety of signaling pathways including mobilization of intracellular calcium, opening of calcium ion channels, activation of NADPH oxidase, transactivation of the EGF receptor, and activation of mitogen-activated protein (MAP) kinase cascades [48]. Increased activation of EGF receptors and mitogen-activated protein kinases is found in many cancer cell types [49]. Additionally, the $\mathrm{AT}_{1}$ receptor has some constitutive activity as well as being activated by stretch independently of Ang II [50].

1.3.8. $\mathrm{AT}_{2}$ Receptor, Ang II Receptor Subtype (Classical): AGTR2. The $\mathrm{AT}_{2}$ receptor also has a $\mathrm{G}$ protein-coupled receptor motif, but it behaves in an idiosyncratic fashion $[51,52]$. The most interesting characteristic of the $\mathrm{AT}_{2}$ receptor is that its actions tend to oppose those of the AT1R [50, 53]. For example, the $\mathrm{AT}_{2}$ receptor activates phosphatase activity and opens a potassium channel, which inhibits cellular activation [54]. The $\mathrm{AT}_{2}$ receptor is highly expressed in utero $[55,56]$, but it has a limited expression in the postnatal period. It is also expressed on atretic follicles [57]. Like the $\mathrm{AT}_{1}$ receptor, the $\mathrm{AT}_{2}$ receptor is also constitutively active and may respond to ligands other than Ang II $[50,58]$.

1.3.9. MAS Protein (Ang 1-7 Receptor) (Neoclassical): MAS1. Mas encodes a class A seven-transmembrane-spanning Gprotein-coupled receptor, identified as a receptor for Ang 17 [59], which is a peptide derived from Ang II by the actions of ACE2 [43] and prolylcarboxypeptidase, formerly known as angiotensinase C [47]. Mas plays a role in multiple processes, including vasodilation with reduction of blood pressure, thereby exhibiting cardioprotective properties by mediating the effects of Ang 1-7 [59]. Thus far, a decrease in MAS1 expression has been associated with tumor growth, lymph node metastasis, and grade of invasive ductal carcinoma [60], while treatment with Ang 1-7 is reported to reduce breast tumor volume [61].

1.3.10. Aminopeptidases (Neoclassical). The two primary aminopeptidases acting upon angiotensin peptides are aminopeptidase A (APA), encoded by ENPEP, and aminopeptidase $\mathrm{N}(\mathrm{APN})$, encoded by ANPEP.

Aminopeptidase A, also known as glutamyl aminopeptidase, releases amino-terminal Glu and Asp residues from proteins and peptides. Aminopeptidase A is found diffusely throughout the brush borders of intestinal enterocytes [62]. Aminopeptidase A converts Ang II to angiotensin III (Ang III), which is reported to be equipotent to Ang II at both the $\mathrm{AT}_{1}$ and $\mathrm{AT}_{2}$ receptors [63]. In the brain, Ang III is reported to be the primary effector of vasopressin release $[64,65]$ although this has been disputed [66].

Aminopeptidase N, also known as CD13, is a multifunctional enzyme that is present in many different human tissues. It serves as a receptor for several viruses including a coronavirus that causes colds $[67,68]$. It plays a significant role in trimming of antigens and is involved in antigen presentation; it can also influence immune functions including angiogenesis and cell proliferation [67]. Aminopeptidase N is known to serve a role in the processing of various peptides including conversion of Ang III to angiotensin IV (Ang IV) as well as metabolizing different chemokines and playing a role in the final digestion of peptides derived from gastric and pancreatic processes [69]. With respect to the RAS, its primary role is to metabolize Ang III to Ang IV, which terminates the ability of the Ang peptide to activate the $\mathrm{AT}_{1}$ and $\mathrm{AT}_{2}$ receptors. Metabolism of Ang IV to the pentapeptide (Ang 4-8) and smaller fragments by other aminopeptidases generates angiotensin peptides for which no function has yet been identified.

1.3.11. $\mathrm{AT}_{4}$ Receptor, Insulin-Regulated Aminopeptidase (Neoclassical): LNPEP. The $\mathrm{AT}_{4}$ receptor, akin to the prorenin receptor, was previously characterized under a different name based upon a different functionality. The $\mathrm{AT}_{4}$ receptor is better known as insulin-regulated aminopeptidase (IRAP) [70, 71]. It is a membrane-bound aminopeptidase that associates with GLUT-4, which is involved in glucose transport. It is a multifunctional peptidase whose substrates include vasopressin and oxytocin. When Ang IV binds to IRAP, it inhibits its peptidase activity. It is suggested that the pharmacological actions of Ang IV may be attributable to an increased abundance of IRAP's substrates [72]. A second type of receptor for Ang IV was identified as c-met, the receptor for the hepatocyte growth factor [73], at which Ang IV is also reported to act as an inhibitor. Additional potential receptors for Ang IV are several Mas-related $\mathrm{G}$ protein-coupled receptor-like proteins, e.g., MrgD, MrgH, and MRG [74].

1.3.12. Endopeptidases That Act upon Angiotensin Peptides. Several endopeptidases metabolize angiotensin peptides. With respect to the functionality of the RAS, four endopeptidases metabolize Ang I to Ang 1-7: neprilysin, thimet oligopeptidase, neurolysin, and prolyl endopeptidase [75].

(1) Neprilysin (Neoclassical). MME is a neutral endopeptidase that is highly expressed in kidney and lung tissues. Neprilysin is responsible for inactivating many regulatory peptides of the mammalian nervous, cardiovascular, inflammatory, and immune systems [76]. By inhibiting neprilysin, the bioavailability of natriuretic peptides, bradykinin, and substance $\mathrm{P}$ increases. As a result, these effects allow an effective antihypertensive response. A neprilysin inhibitor (sacubitril) is being used clinically to treat congestive heart failure in 
combination with the angiotensin receptor blocker valsartan [77]. The beneficial effects of neprilysin inhibition suggest that the preservation of natriuretic peptides outweighs the reduction in Ang 1-7 formation from Ang I.

(2) Thimet Oligopeptidase (Neoclassical). THOP is a neuropeptidase in the metallopeptidase family that is responsible for forming enkephalins, while degrading other peptides [78]. Thimet oligopeptidase preferentially metabolizes neuropeptides under 20-amino acid residue long and forms Ang 1-7 from Ang I [79].

(3) Neurolysin (Neoclassical). NLN is an oligopeptidase that hydrolyzes many different peptides including neurotensin, bradykinin, and dynorphin A [80]. Neurotensin is particularly important because it regulates luteinizing hormone (LH), prolactin release, and blood pressure; it may also be neuroprotective in stroke [81]. It can both form Ang 1-7 from Ang I as well as cleave Ang II and likely other angiotensin peptides at the Tyr-Ile bond [80].

(4) Prolyl Endopeptidase (Prolyl Oligopeptidase) (Neoclassical). PREP is serine peptidase that cleaves peptides distal to the carboxy end of a proline [82]. It can metabolize both Ang I and Ang II to form Ang 1-9 and Ang 1-7. It also can metabolize Ang III and Ang IV to the corresponding des Phe metabolites [82].

\section{Materials and Methods}

Seventeen genes (Figures 2-4, S1-S2) of the RAS and related enzymes were selected for analysis in 148 laser capture microresected (LCM) and homogenized tissue samples of male patients with CRC [83]. The quantitative expression of the RNA of these 17 genes in normal and cancerous tissue samples was obtained using chip arrays from the public functional genomics data repository, Gene Expression Omnibus (GEO) application. There were 24 pairs of normal tissue and cancerous tissue arrays available for analysis of these specific genes.

2.1. Statistical Analysis. We analyzed the $\log _{2}$ RNA expression of the selected genes in normal and cancerous tissues for statistical significance using a paired $t$-test with GraphPad Prism software (version 8.0 for windows, GraphPad Inc., San Diego, California, USA).

In some cases, the data was not normally distributed based upon the D'Agostino and Pearson normality test and/or the Shapiro-Wilk normality test, whereupon comparisons between the normal and cancer tissue were made using the Wilcoxon matched-pairs signed rank test with GraphPad Prism software (version 8.0 for windows, GraphPad Inc., San Diego, California, USA). The nonnormally distributed expression of RAS-related genes in the tumor samples were ATP6AP2 (prorenin receptor), PREP (prolyl endopeptidase), $L N P E P$ (Ang IV receptor), and NLN (neurolysin) which were negatively skewed, as well as ANPEP (aminopeptidase N) which was positively skewed. Of note, two normal tissue gene expression distributions were also nonnormally distributed: PREP (prolyl endopeptidase), which was negatively skewed, and LNPEP (Ang IV receptor), which was positively skewed. All the nonnormally distributed genes showed kurtosis, meaning that there was an excess of values to the left or right of the average depending on whether the values were negatively or positively skewed, respectively.

Two levels of significance are reported: one which is not corrected for multiple comparison in view of the large number of comparisons that were made and one that was corrected for the multiple comparisons (Figures 2-4, S1-S2). The uncorrected significance level is reported because the likelihood of making a type II error (failure to reject a false null hypothesis) increases with the number of multiple comparisons, albeit the chances of making a type I error (failure to accept a true null hypothesis) also increases. For 17 comparisons using the Sidak's correction at a level of $p \leq 0.05$ after correction, the significance level would need to be $p<$ $0.003013=\left[1-(1-0.05)^{1 / 17}\right]$. For $p<0.01$ after correction, the significance level would need to be $p<0.000591=[1-$ $\left.(1-0.01)^{1 / 17}\right]$.

Tissue stages of tumor samples were based upon TNM staging as described by Tsukamoto et al. [83]. All nonredundant tumor samples $(N=108)$ were analyzed with $\log _{2}$ RNA expression of the 17 genes at different stages of cancer using a one-way ANOVA with post hoc Bonferroni comparisons. Values shown are mean \pm SEM or median where the sample set did not have a normal distribution.

2.2. Literature Search Terms. The literature search used PubMed with the following key words: renin-angiotensin system, colorectal cancer, angiotensin metabolism, and angiotensin receptors, in combination or alone, with/without the additional search term review. In addition, derivative references were obtained from review articles found in the original literature search.

\section{Results}

3.1. Gene Expression in Normal versus Cancerous Colorectal Tissue. The changes in gene expression for each of the 17 RAS-related genes are described in Figures 2-4, S1-S2, and Table 1. Both the corrected and uncorrected levels of significance are shown with corrected levels indicated as $p<0.05$ or $p<0.01$ in Table 1 . Genes of the classical RAS showing significant differences at the $p<0.01$ level after correction are shown in Figure 2, while genes encoding nonclassical RASrelated proteins showing significant differences at the $p<$ 0.01 level after correction are shown in Figure 3. Genes encoding prorenin receptor (ATP6AP2) and aminopeptidase A $(E N P E P)$ which showed significant differences at the $p<$ 0.05 level after correction are displayed in Figure 4. The remaining gene expression values which were not significant after correction for multiple comparisons are reported in Figures S1-S2.

There were significant increases in gene expression for angiotensinogen $(A G T)$, aminopeptidase A (ENPEP), prorenin receptor $(A T P 6 A P 2)$, neprilysin $(M M E)$, and prolyl endopeptidase $(P R E P)$, while there were significant decreases in gene expression for renin $(R E N)$, aminopeptidase $\mathrm{N}$ 
Angiotensinogen (AGT)

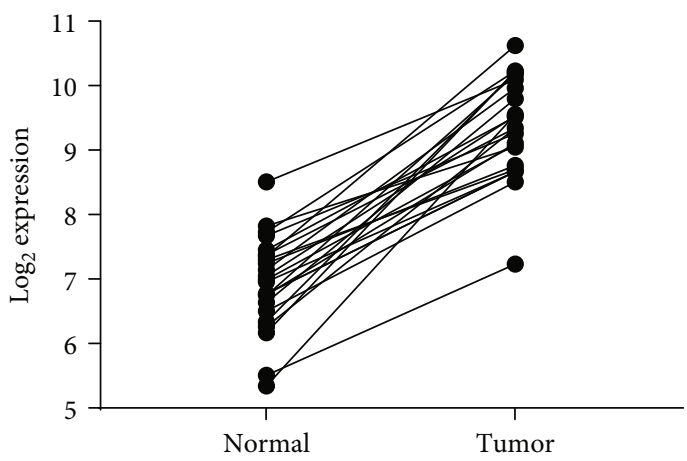

(a)

Renin (REN)

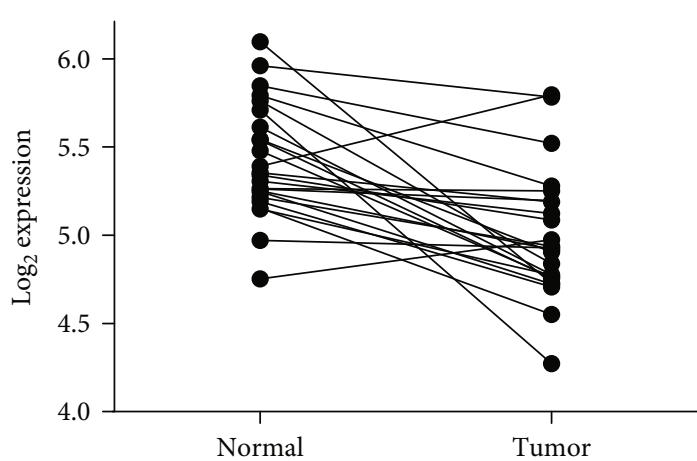

(c)

Mas receptor (Mas1)

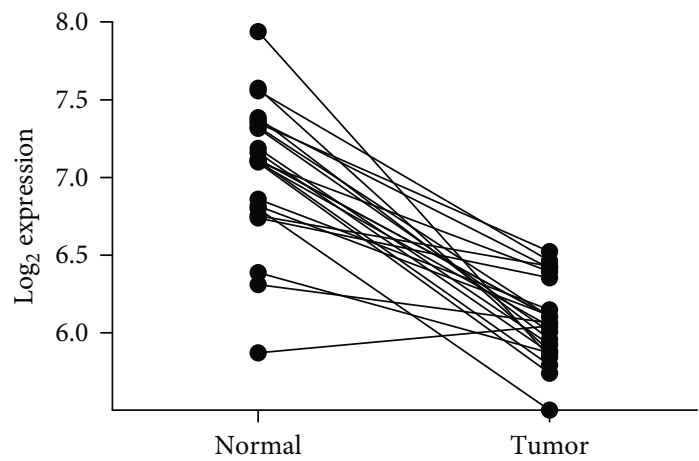

(e)
Angiotensinogen (AGT)

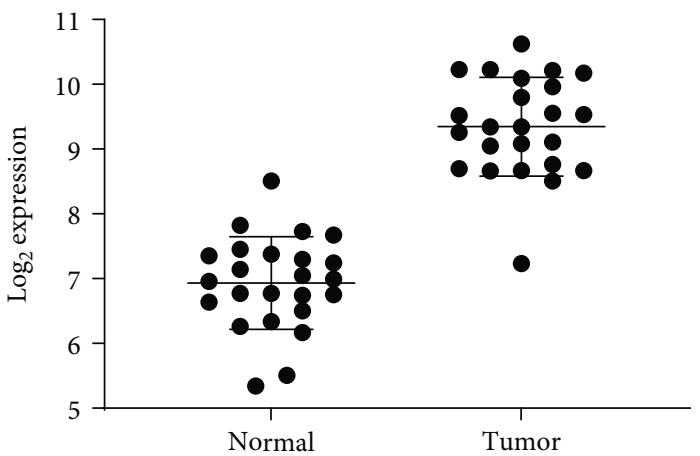

(b)

Renin (REN)

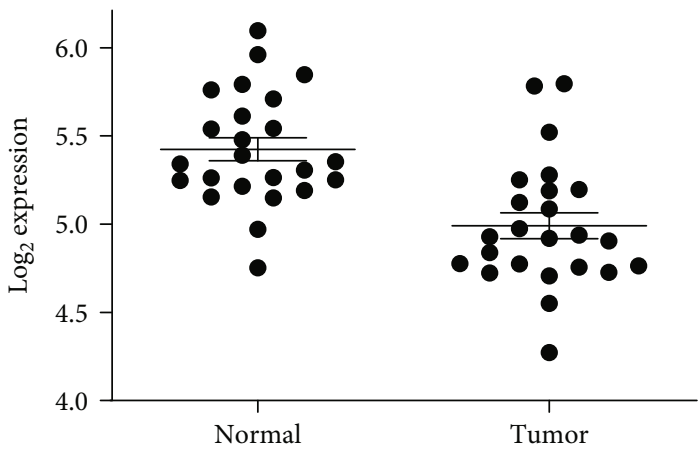

(d)

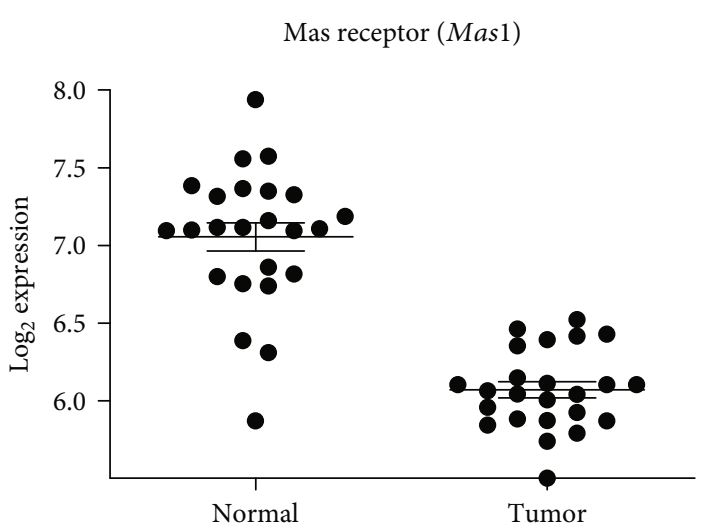

(f)

FIGURE 2: RAS components that showed highly significant differences in gene expression between normal and tumor tissues. (a, b) Describe angiotensinogen gene $(A G T)$ expression, $(c, d)$ describe renin gene $(R E N)$ expression, and $(\mathrm{e}, \mathrm{f})$ describe Mas receptor gene $(M A S 1)$ expression. (a, c, and e) Show pairing of samples with connecting lines. (b, d, and f) Show mean, SEM, and individual data points. All of these comparisons were significant at the $p<0.01$ level after correction for multiple comparisons.

$(A N P E P)$, Mas receptor (MAS1), thimet oligopeptidase $(T H O P)$, and neurolysin $(N L N)$. There were nonsignificant (after correction for multiple comparisons) trends for increases in gene expression for prolylcarboxypeptidase $(P R C P)$ and the $\mathrm{AT}_{2}$ receptor (AGTR2), while there were similarly nonsignificant trends for decreases in gene expression for angiotensin-converting enzyme $(A C E)$ and chymase (CMA1).
The relative expression of genes of the RAS and RASrelated enzymes varied considerably in tumor tissue (Table 1, Figures 2-4, and S1, S2), with the prorenin receptor having the highest expression followed by prolyl endopeptidase, ACE2, and angiotensinogen. The lowest relative expression of genes of the RAS and RAS-related enzymes was chymase, with renin and the $\mathrm{AT}_{2}$ receptor also showing low relative expression. 


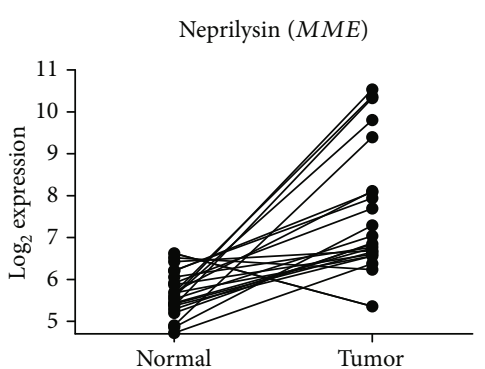

(a)

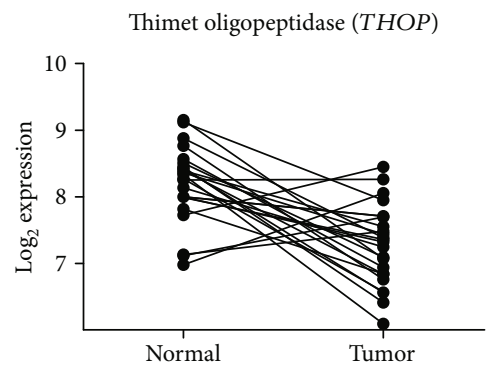

(c)

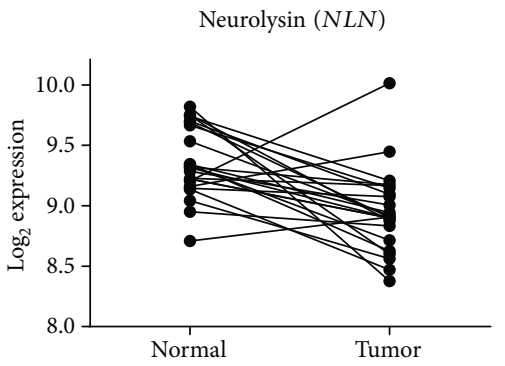

(e)

Prolyl endopeptidase (PREP)

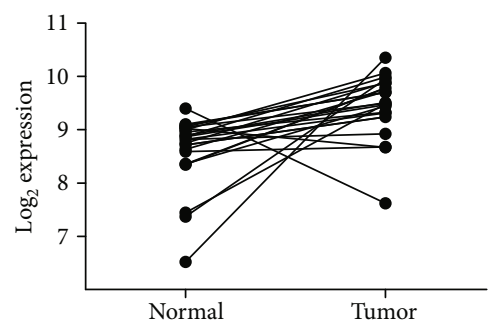

(g)

Aminopeptidase $\mathrm{N}$ (ANPEP)

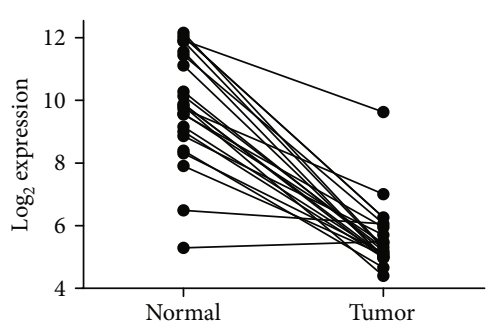

(i)

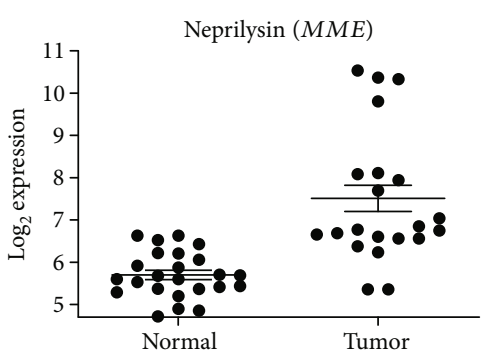

(b)

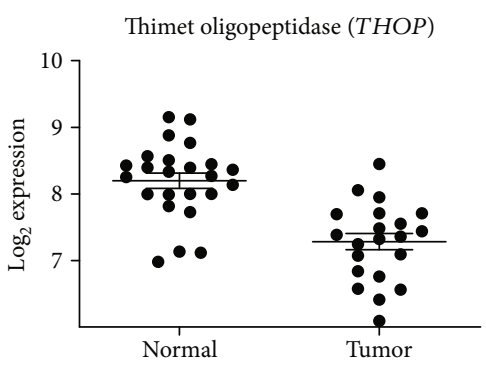

(d)

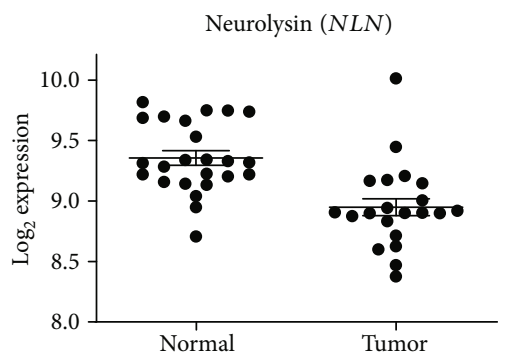

(f)

Prolyl endopeptidase (PREP)

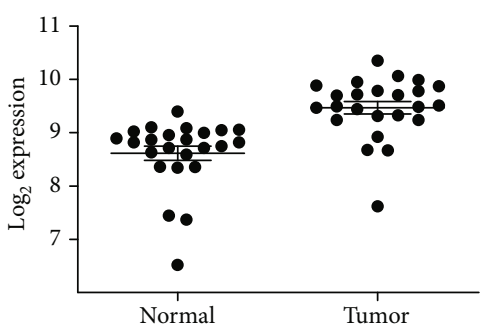

(h)

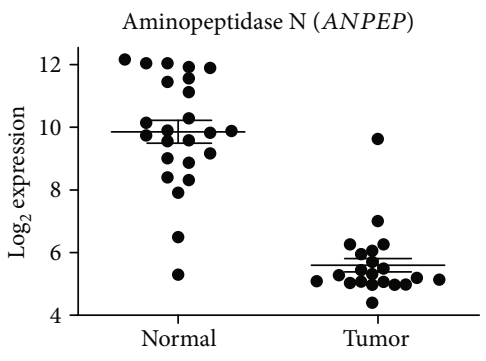

(j)

FIGURE 3: RAS-related enzymes that showed highly significant differences in gene expression between normal and tumor tissues. (a-j) Describe neprilysin gene $(M M E)$ expression, thimet oligopeptidase gene (THOP) expression, neurolysin gene (NLN) expression, prolyl endopeptidase gene (PREP) expression, and aminopeptidase $\mathrm{N}$ gene (ANPEP) expression. (a, $\mathrm{c}, \mathrm{e}, \mathrm{g}$, and $\mathrm{i}$ ) Show pairing of samples with connecting lines. (b, $d, f, h$, and j) Show mean, SEM, and individual data points. All of these comparisons were significant at the $p<0.01$ level after correction for multiple comparisons. 
Prorenin receptor (ATP6AP2)

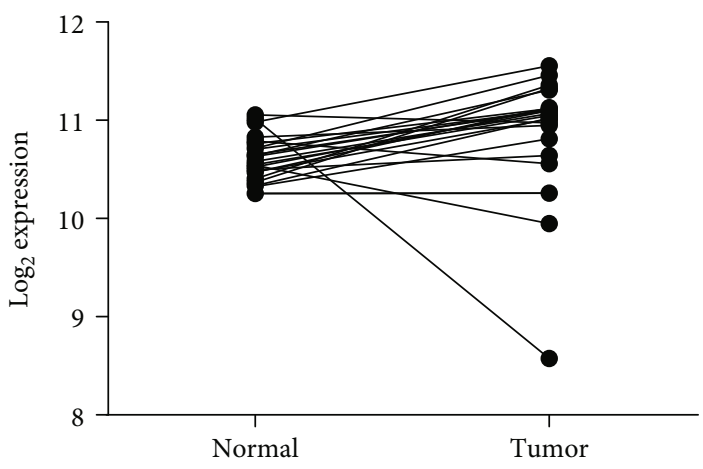

(a)

Aminopeptidase A (ENPEP)

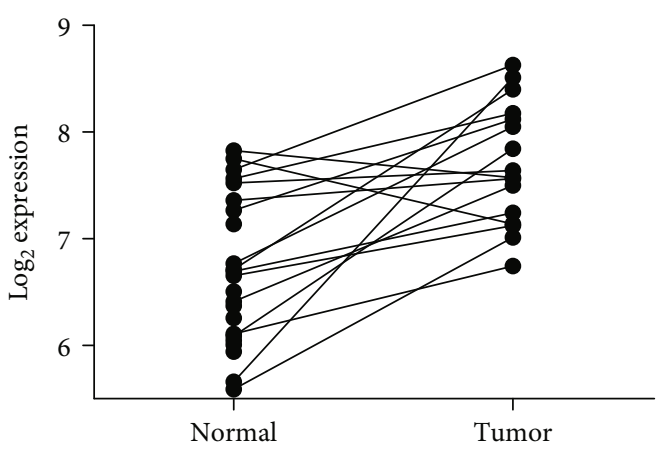

(c)
Prorenin receptor (ATP6AP2)

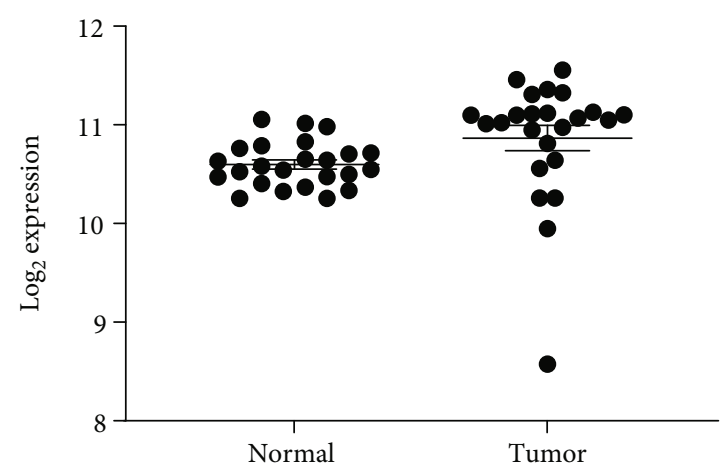

(b)

Aminopeptidase A (ENPEP)

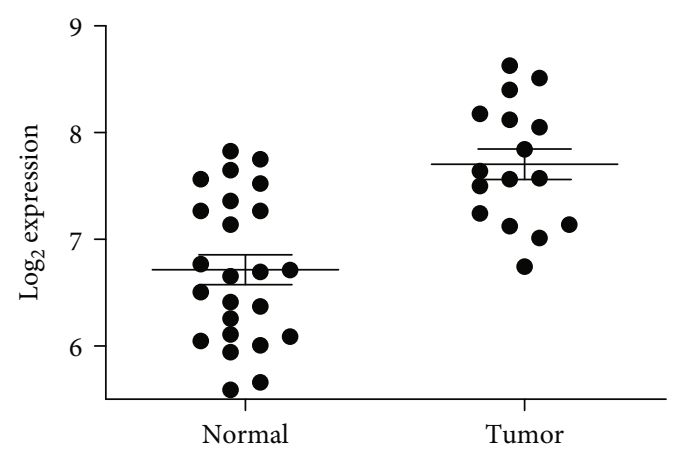

(d)

FIGURE 4: RAS-related components that showed significant $(p<0.05)$ differences in gene expression between normal and tumor tissues. $(a, b)$ Describe prorenin receptor gene (ATP6AP2) expression, and (c, d) describe aminopeptidase A gene (ENPEP) expression. (a, c) Show pairing of samples with connecting lines. (b, d) Show mean, SEM, and individual data points. All of these comparisons wesssre significant at the $p$ $<0.05$ level after correction for multiple comparisons.

There were no systematic differences in relative gene expression of the RAS and RAS-related enzymes with the stage of the tumor. There was a marginally significant reduction in gene expression for $P R C P, A C E 2$, and $A G T$ in stage $2 \mathrm{~B}$ relative to stage 1 , but this did not approach statistical significance for a multiple comparison correction. In general, gene expression was consistent for all genes surveyed across all stages and did not show evidence for trends toward increases or decreases with increasing stage number. A representative example wherein expression of $A G T$ in stage $2 \mathrm{~B}$ was significantly lower than those in stages 1 and $4(p<0.01)$ by post hoc Bonferroni comparison is shown in Figure S3.

3.1.1. Angiotensinogen (AGT). There was a large highly significant increase of $2.413 \mathrm{log}$ units in $A G T$ gene expression suggesting increased production of the angiotensinogen precursor of the angiotensin peptides in colorectal tumor tissue (Table 1).

3.1.2. Renin (REN). There was a highly significant reduction of $-0.4336 \log$ units of $R E N$ gene expression, which could indicate reduced Ang I formation and buildup of angiotensinogen (Table 1).
3.1.3. Prorenin Receptor (ATP6AP2). There was no significant change in expression of this receptor in normal versus cancerous tissue samples.

3.1.4. Chymase (CMA1). There was no significant change in expression of this receptor in normal versus cancerous tissue samples.

3.1.5. Neprilysin (MME). There was a highly significant increase of $1.809 \log$ units in neprilysin (CD10, CALLA) gene expression in colorectal tumor tissue (Table 1). Neprilysin metabolizes Ang I to form Ang 1-7, competing with ACE, thereby reducing the formation of Ang II. However, neprilysin metabolizes a wide variety of peptides including atrial natriuretic peptide which is the basis for the use of sacubitril, a neprilysin inhibitor in the heart failure drug, Entresto ${ }^{\circledR}$.

3.1.6. Neurolysin (NLN). Neurolysin has a similar role in the RAS as neprilysin $(M M E)$. There was a highly significant decrease, $-0.41 \log$ units, in expression of NLN in CRC tissues (Table 1). In view of the increased expression of $M M E$ and decreased expression of $N L N$, but with higher gene expression of $N L N$ (Table 1), the change in formation of Ang 1-7 from Ang I would likely be small. 


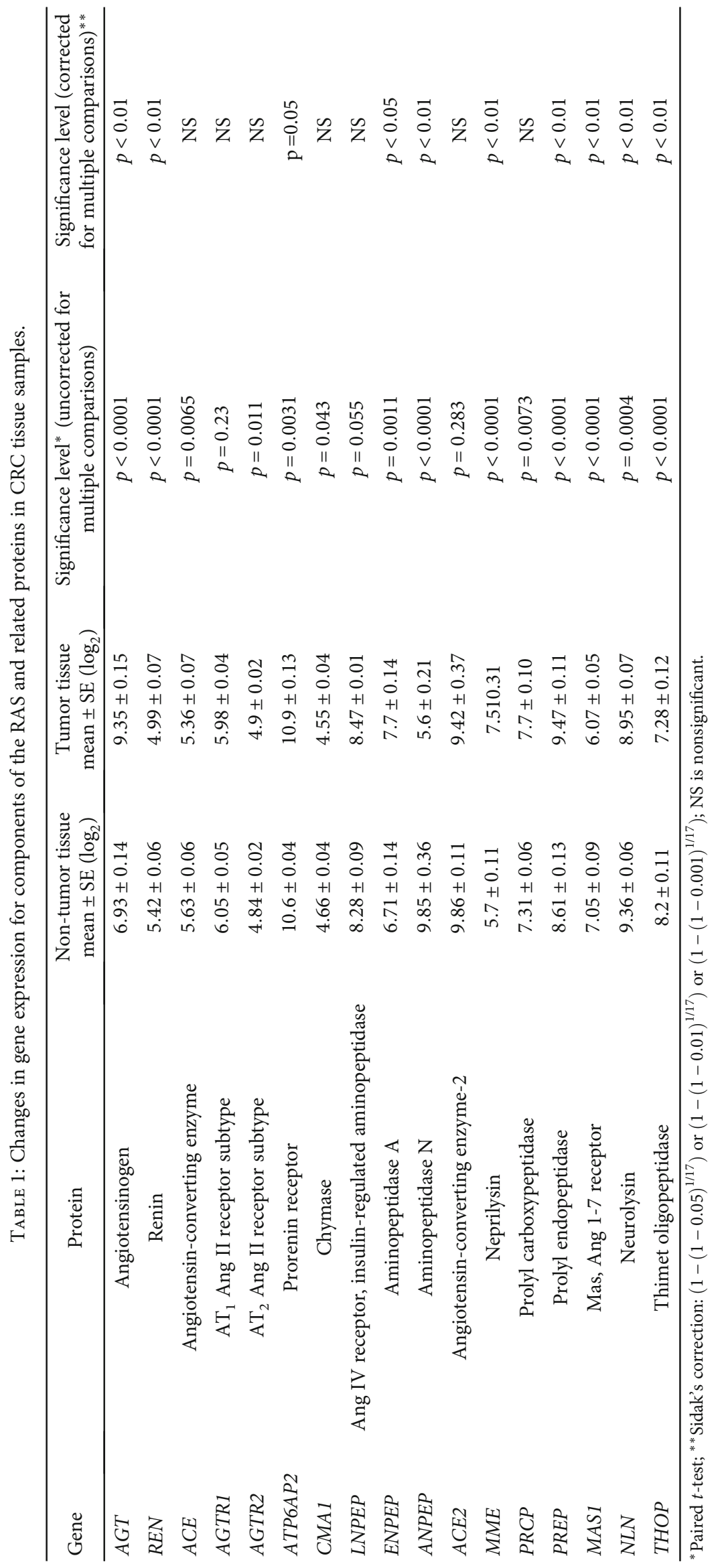


3.1.7. Angiotensin-Converting Enzyme (ACE). There was a decrease in expression of $A C E$ gene in CRC tissues that was significant only in the uncorrected comparison (Table 1). $\mathrm{ACE}$ is responsible for the conversion of Ang I to Ang II. A decrease of ACE expression in CRC tissues implies a reduction in the conversion of Ang I to Ang II, known for its vasoconstrictive properties.

3.1.8. Angiotensin-Converting Enzyme 2 (ACE2). There was an insignificant decrease in expression of ACE2 gene in CRC tissues. ACE2 inactivates Ang II by forming Ang 1-7, the putative agonist for the Mas receptor.

3.1.9. Thimet Oligopeptidase (THOP). There was no significant change in expression of this enzyme in normal versus cancerous tissue samples.

3.1.10. Aminopeptidase A (ENPEP)/Aminopeptidase $N$ (ANPEP). There was a significant increase of $-0.9306 \mathrm{log}$ units in ENPEP gene expression, suggesting an increase in aminopeptidase A-mediated conversion of Ang II to Ang III. Additionally, there was a highly significant decrease of $4.253 \mathrm{log}$ units in ANPEP gene expression, suggesting a decrease in aminopeptidase N-mediated conversion of Ang III to Ang IV. These changes would greatly increase the amount of Ang III in tumor tissue, which could indicate that Ang III might be a better tumor promoter than Ang II.

3.1.11. $\mathrm{AT}_{4}$ Receptor/Insulin-Related Aminopeptidase (LNPEP). There was no significant change in expression of this receptor/enzyme in normal versus cancerous tissue samples.

3.1.12. Prolyl Carboxypeptidase (PRCP). There was an increase in $P R C P$ gene expression in CRC tissue samples compared to their normal counterpart, but it was significant only in the uncorrected comparison (Table 1). PRCP also mediates inactivation of Ang II by metabolizing it to Ang $1-7$.

3.1.13. Prolyl Endopeptidase (PREP). There was no significant change in expression of this enzyme in normal versus cancerous tissue samples.

3.1.14. Type 1 AT1R Ang II Receptor (AGTR1) and Type 2 AT2R Ang II Receptor (AGTR2). $\mathrm{AT}_{1}$ and $\mathrm{AT}_{2}$ receptor gene expression was unchanged in normal and in cancerous tissues.

3.1.15. Mas (MAS1). There was a highly significant reduction of $0.985 \log$ units in MAS1 gene expression in CRC tissue.

\section{Discussion}

Components of the modern-day RAS (Figure 1) and their role in various cancer pathways have been described recently with attention to the quantitative expression of genes in cancerous tissues and their normal tissue counterparts. Multiple studies have described a possible role of the RAS in various types of cancer, including lung cancer, breast cancer [60, 84-87], CRC, and CRC liver metastases [15, 27] (Table 2).
There is considerable evidence of a relationship between polymorphisms in ACE and gastric cancer [88], lung cancer $[89,90]$, prostate cancer [91], and cancer in general [92].

We were particularly interested in recent studies that describe the RAS in CRC primary and metastatic tissues. The studies that focused on RAS components in CRC generally found a consistent correlation between RAS-related gene expression in CRC tissues with ACE, MasR, AT1R, and AT2R expression being altered in CRC primary and metastatic tissues $[15,27]$. Protumoral associations of the RAS proteins may be related to gliomas as well [26].

We observed statistically significant alterations in gene expression of many, but not all, RAS-related components in CRC specimens. The significant increase in angiotensinogen gene expression in the CRC (Figure 2) is suggestive of an increased supply of the precursor protein of the RAS leading to a general increase in activity of the system. However, the genes encoding the enzymes that process angiotensinogen, renin and ACE, to form Ang II, are decreased in the CRC samples compared to normal tissue, so it is not possible to speculate whether Ang II formation is increased or decreased. It is possible that there may be non-RASmediated effects of the increased angiotensinogen in the CRC tissues. Both angiotensinogen and des-Ang I angiotensinogen promote weight gain and liver steatosis in mice that are independent of the RAS [93]. Interestingly, angiotensinogen-deficient mice exhibited an increase in vascular endothelial growth factor A (VEGF-1) which may imply that overexpression of angiotensinogen could have an antiangiogenic effect [93].

Medications that target ACE and angiotensin receptors, such as angiotensin-converting enzyme inhibitors (ACEIs) and angiotensin receptor blockers (ARBs), respectively, are widely used as antihypertensive agents and therapies for patients with heart failure and diabetic complications [94]. Newer therapeutic agents have emerged that inhibit other components of the RAS, such as neprilysin, although neprilysin has a variety of peptide substrates other than angiotensins. Accordingly, if the proteins encoded by the RAS genes play a significant role in CRC pathophysiology, then, already existing therapies could potentially treat CRC.

The expression of genes encoding the major receptors for angiotensin peptides, AT1R and AT2R, was not different between tumor and normal tissue samples (Figures S1 and S2) which might argue against a major pathophysiological involvement of the classical RAS in CRC despite the mitogenic potential of AT1R signaling [95]. Increased AGTR1 gene expression is associated with breast cancer [85], and ARBs inhibit mammary tumor formation in mice $[86,87]$. Similar, to the observation of no increase in AT1R gene expression in this study, ARB usage did not have a protective effect against CRC in a retrospective study of a large Spanish population [96].

Receptor stimulation also depends upon agonist availability, which is subject to regulation by metabolic activity. Relevant to angiotensins, there is a substantial increase in aminopeptidase A gene expression. Aminopeptidase A is the enzyme that metabolizes Ang II to form Ang III, suggesting a reduction in the degree to which Ang II would be able to 
TABLE 2: Change of the RAS gene expression in various cancers.

\begin{tabular}{|c|c|c|c|c|}
\hline Cancer type & RAS gene & RAS protein & Change & Citation \\
\hline $\begin{array}{l}\text { Invasive duct cell } \\
\text { breast cancer }\end{array}$ & $M M P$ & Neprilysin & Downregulated & Stephen et al. [113] \\
\hline \multirow{5}{*}{ CRC liver metastases } & AGTR1 & AT1R & Upregulated & $\begin{array}{l}\text { Neo et al. [15], Zhou } \\
\text { et al. [27] }\end{array}$ \\
\hline & AGTR2 & AT2R & Upregulated & Neo et al. [15] \\
\hline & $A G T$ & Angiotensinogen & No change & Neo et al. [15] \\
\hline & $A C E$ & $\begin{array}{l}\text { Angiotensin- } \\
\text { converting enzyme }\end{array}$ & Upregulated & Neo et al. [15] \\
\hline & MAS1 & Mas receptor & Upregulated & Neo et al. [15] \\
\hline \multirow{3}{*}{ CRC } & AGTR1 & AT1R & $\begin{array}{l}\text { Upregulated, protumoral, and dose dependent on } \\
\text { Ang II concentration }\end{array}$ & Zhou et al. [27] \\
\hline & AGTR2 & AT2R & $\begin{array}{c}\text { Biphasic, Ang II dose dependent (low = protumoral, } \\
\text { high = antitumoral) }\end{array}$ & Zhou et al. [27] \\
\hline & AGTR2 & AT2R & $\begin{array}{l}\text { Protumor at low (Ang II), antitumoral effects at high } \\
\text { (Ang II) }\end{array}$ & Zhou et al. [27] \\
\hline Breast cancer & AGTR2 & AT2R & Upregulated & Zhou et al. [27] \\
\hline Pancreatic cancer & $\begin{array}{l}\text { AGTR2 via } \\
\text { ATII }\end{array}$ & AT2R via ATII & Upregulated & Zhou et al. [27] \\
\hline $\begin{array}{l}\text { Chemically induced } \\
\text { lung cancer }\end{array}$ & AGTR2 & AT2R & Upregulated & Zhou et al. [27] \\
\hline $\begin{array}{l}\text { CRC, lymph node } \\
\text { metastases }\end{array}$ & $A C E$ & $\begin{array}{c}\text { Angiotensin- } \\
\text { converting enzyme }\end{array}$ & Allele dependent & Zheng et al. [16] \\
\hline
\end{tabular}

stimulate $\mathrm{AT}_{1}$ and $\mathrm{AT}_{2}$ receptors. With respect to Ang III, there was a profound decrease in aminopeptidase $\mathrm{N}$ gene expression in the tumor tissue. Aminopeptidase $\mathrm{N}$ is the major inactivating enzyme for Ang III, so a reduction in its expression coupled with an increase in aminopeptidase A expression would cause a substantial accumulation of Ang III-mediated activation of $\mathrm{AT}_{1}$ and $\mathrm{AT}_{2}$ receptors. Also, reduced activity of aminopeptidase $\mathrm{N}$ would decrease Ang IV formation, reducing stimulation of the $\mathrm{AT}_{4}$ receptor. However, there was also no significant change in $\mathrm{AT}_{4}$ receptor gene expression, making it unlikely that there was a significant alteration in $\mathrm{AT}_{4}$ receptor signaling in the CRC tumor tissue. Of note, blockade of aminopeptidase $\mathrm{A}$ in the brain is reported to decrease stimulation of $\mathrm{AT}_{1}$ receptors, implying that Ang III is a more efficacious agonist than Ang II on brain $\mathrm{AT}_{1}$ receptors $[65,97]$. Ang III was reported to be more potent than Ang II in the rat brain [98], although Ang III is generally considered to be near equipotent with Ang II as an $\mathrm{AT}_{1}$ receptor agonist [63]. Also, it was recently shown that Ang II and Ang III signal at $\mathrm{AT}_{1}$ receptors with similar potency for $\mathrm{G}$ protein and beta-arrestin-mediated signaling pathway profiles [99]. Thus, the evidence for involvement of altered $\mathrm{AT}_{1}$ or $\mathrm{AT}_{2}$ receptor activation in tumor tissue in this cohort is mixed.

Studies have previously demonstrated that established therapies, particularly ACE inhibitors and ARBs, have a role in reducing the risk of cancers, improving cancer survival outcomes, delaying progression of invasive cancers, and decreasing the quantity of tumor metastasis $[15,17,18,27$,
$86,100,101]$. These studies have looked at RAS-related medications in CRC and CRC metastasis, adenomatous polyps, breast, prostate, renal, and small cell cancers (Table 3).

ACEIs or ARBs, when used in conjunction with COX-2selective inhibitors, resulted in the downregulation of tumor growth in CRC patients [17]. Additionally, they found that when used for 3 or more years, ACEIs or ARBs each resulted in a decreased risk of CRC, while CCBs used for 3 or more years resulted in no change in risk for CRC. ACEI use was found to reduce adenomatous polyps (APs) in a doserelated manner, thereby decreasing the risk of CRC via the downregulation of these CRC precursors [18].

ACEIs were shown to improve survival outcomes in breast, prostate, renal, and small cell cancers, while losartan, an ARB, slowed the invasiveness of breast cancer tumors [86]. The ACEI captopril reduced the volume of liver metastases in a mouse model of CRC [15]. However, when ACEIs and ARBs are used together, [101] there is a paradoxical increased risk of developing cancer. Fortunately, this combination of medications is rarely seen in clinical practice, because it causes more adverse drug reactions than treatment with an ACE inhibitor or ARB alone, with no improvements in key outcomes [102].

The gene expression data predicts significant alterations in RAS components in this CRC population. While we did not observe any changes in gene expression for $\mathrm{AT}_{1}$ and $\mathrm{AT}_{2}$ receptors, there were alterations in the generation and metabolism of angiotensin peptides in CRC tumor tissues that could affect $\mathrm{AT}_{1}$ and $\mathrm{AT}_{2}$ receptor signaling. It remains 
TABLE 3: Use of RAS inhibitors and other medications in various cancers.

\begin{tabular}{|c|c|c|c|}
\hline Medication & Cancer type & Effect of medication on cancer type & Citation \\
\hline $\begin{array}{l}\text { ACEI/ARBs + COX - } 2 \\
\text { inhibitors }\end{array}$ & CRC & Downregulated tumor growth & Makar et al. [17] \\
\hline ACEI/ARB $\geq 3$ years & $\mathrm{CRC}$ & Decreased RISK of CRC & Makar et al. [17] \\
\hline CCB $($ high dose $) \geq 3$ years & CRC & No change & Makar et al. [17] \\
\hline $\begin{array}{l}\text { Statins, ACEI, CCBs, } \\
\text { diuretics }\end{array}$ & $\mathrm{CRC}$ & No change in risk of CRC & $\begin{array}{l}\text { Boudreau et al. } \\
\quad[100]\end{array}$ \\
\hline ACEI (dose related) & Adenomatous polyps & $\begin{array}{c}\text { Decreased risk of CRC via downregulation of } \\
\text { adenomatous polyps }\end{array}$ & Kedika et al. [18] \\
\hline $\begin{array}{l}\text { ACEI and ARB } \\
\text { combination }\end{array}$ & Cancer (nonspecific) & Increased risk of cancer & $\begin{array}{l}\text { Bangalore et al. } \\
{[101]}\end{array}$ \\
\hline ACEI & $\begin{array}{l}\text { Breast, prostate, renal, and small } \\
\text { cell cancer }\end{array}$ & Improved survival outcomes & $\begin{array}{l}\text { Coulson et al. } \\
\qquad[86]\end{array}$ \\
\hline Losartan (ARB) & Breast Cancer & $\begin{array}{l}\text { Delays occurrence and progression of invasive breast } \\
\text { cancer }\end{array}$ & $\begin{array}{l}\text { Coulson et al. } \\
\qquad[86]\end{array}$ \\
\hline Captopril (ACEI) & CRC liver metastases & Decreased tumor metastases & Neo et al. [15] \\
\hline
\end{tabular}

to be seen whether there is a genetic or environmental determinant of the tumor tissue gene expression that translates to a more robust response to therapies that block the RAS and if there is a dose-dependent mechanism that would provide patients with an optimum response to therapy. In addition, patient compliance and duration of therapy remain as possible confounders to individual patient responses. Our study further demonstrates that the RAS potentially plays a role in CRC and that the use of well-studied RAS-directed therapies, such as ACEIs, ARBs, and renin inhibitors, may be of benefit for adjunctive treatment of CRC. It is worth mentioning that many trials have been run to determine if RAS blockers can cause cancer and the evidence is overwhelmingly against any relation between RAS blockers and increased risk of cancer in general [103-106].

ACE gene expression was marginally significantly reduced in the CRC tumor samples, i.e., it was significant on its own, but not with the multiple comparison correction. This observation is in contrast to a previous study which showed an increase in ACE mRNA expression in CRC [107]. The involvement of ACE activity in tumors may be tumor specific or limited to specific ethnic groups. Having the DD (deletion) genotype of the ACE gene confers increased ACE activity and is associated with increased lymph node metastasis of CRC in a cohort of Chinese patients [16]. A meta-analysis of studies of the association of the DD and II ACE genotypes, a variety of cancers, suggested that the II ACE genotype was weakly associated with reduced risk of some cancers [108]. There is considerable variance in the reported effects of ACE inhibitors on cancer risk with some studies of CRC showing a chemoprotective effect $[18,109]$. Beneficial effects of ACE inhibitors on CRC were found to be greatest in men under 65 years of age [96].

There was a substantial increase in neprilysin (CD10, CALLA) gene expression in colorectal tumor tissue. Neprilysin metabolizes Ang I to form Ang 1-7, competing with ACE, thereby reducing formation of Ang II. However, neprilysin metabolizes other peptides, which might affect tumorigenesis. Of note, neprilysin is a marker for several cancers, including leukemias [110], and is also inhibited by sacubitril, a component of the heart failure drug, Entresto ${ }^{\circledR}$ (sacubitril/valsartan). It will be of interest to determine if sacubitril or other neprilysin inhibitors affect CRC incidence. There was a substantial reduction in MAS1 gene expression. MAS1 encodes the Mas receptor for angiotensin 1-7 [59], which is reported to have antiproliferative properties [28]. A reduction in Mas receptor expression may facilitate unregulated proliferation of CRC cells [111]. There was also a large increase in $A G T$ gene expression suggesting increased production of the angiotensinogen precursor of the angiotensin peptides in colorectal tumor tissue. However, the reduction in REN could indicate reduced Ang I formation and a build-up of angiotensinogen which might explain the protumor effect of angiotensinogen on CRC metastasis to the liver [112].

Finally, we examined RAS-related gene expression as a function of different stages of CRC. Although in Figure S3, expression of $A G T$ in stage $2 \mathrm{~B}$ was significantly lower than those in stages 1 and 4, gene expression was generally consistent for all genes surveyed across all stages and did not show evidence for trends toward increases or decreases with increasing stage number. This could indicate that the changes in RAS-related components are associated with tumorigenesis rather than progression of CRC. Our current analysis examines the differential genetic expression of a population of CRC patients in Japan. We plan to pursue the evaluation of the expression of these genes in surgically resected samples from locally sourced tissues to determine if the findings will translate across population demographics.

4.1. Limitations of Study. This Japanese population may not generalize to other ethnic groups. Alterations in gene expression do not always translate into significant alterations in protein expression and function. This study did not assess 
$M R G P R D$ expression, which encodes Mas-related G protein receptor family member $\mathrm{D}(\mathrm{MrgD})$, one of the newer receptor components of the RAS.

\section{Conclusion}

This analysis is consistent with the involvement of both the ACE/Ang II/AT1R and ACE2/Ang 1-7/Mas axes of the RAS in CRC. However, the pathological significance of the changes in RAS-related gene expression requires continued assessment of the effects of drugs that inhibit or enhance the activities of these RAS-related components on the incidence and the survivability of CRC.

\section{Abbreviations}

ACE: Angiotensin-converting enzyme

ACE: Angiotensin-converting enzyme gene

ACE2: Angiotensin-converting enzyme-2

ACE2: Angiotensin-converting enzyme-2 gene

ACEI: Angiotensin-converting enzyme inhibitor

AGT: Angiotensinogen gene

AGTR1: $\quad \mathrm{AT}_{1}$ receptor gene

AGTR2: $\quad \mathrm{AT}_{2}$ receptor gene

ANG: Angiotensin

Ang I: Angiotensin I

Ang II: Angiotensin II

Ang III: Angiotensin III

Ang IV: Angiotensin IV

ANPEP: Aminopeptidase $\mathrm{N}$ gene

AP: $\quad$ Adenomatous polyp

ARB: Angiotensin receptor blockers

AT1R: $\quad \mathrm{AT}_{1}$ Ang II receptor subtype

AT2R: $\quad \mathrm{AT}_{2}$ Ang II receptor subtype

ATP6AP2: Prorenin receptor gene

CCB: $\quad$ Calcium channel blockers

CMA1: Chymase gene

COX: Cyclooxygenase

CRC: $\quad$ Colorectal cancer

ENPEP: Aminopeptidase A gene

FAP: $\quad$ Familial adenomatous polyposis

IRAP: Insulin-regulated aminopeptidase

LNPEP: Insulin-regulated aminopeptidase (Ang IV receptor) gene

MAS1: $\quad$ Mas receptor gene

$M M E: \quad$ Neprilysin gene

NLN: Neurolysin gene

PRCP: Prolylcarboxypeptidase

PRCP: $\quad$ Prolyl carboxypeptidase gene

PREP: $\quad$ Prolyl endopeptidase gene

RAS: $\quad$ Renin-angiotensin system

REN: $\quad$ Renin gene

SEM: $\quad$ Standard error of the mean

THOP: Thimet oligopeptidase gene.

\section{Data Availability}

Raw data for this manuscript can be made available upon request for scientific review by qualified parties.

\section{Conflicts of Interest}

The authors declare that they have no conflicts of interest.

\section{Acknowledgments}

Abdullah Almutairy assisted with accessing the gene expression data through the GeneSpring database which was kindly provided by Dr. Jean Latimer.

\section{Supplementary Materials}

Figure S1: RAS components and related enzymes that showed only uncorrected significant differences in gene expression between normal and tumor tissues. From top to bottom, the panels describe angiotensin-converting enzyme gene $(A C E)$ expression, chymase gene (CMA1) expression, $\mathrm{AT}_{2}$ receptor gene (AGTR2) expression, and prolyl carboxypeptidase gene (PRCP) expression; left panels show pairing of samples with connecting lines. Right panels show mean, SEM, and individual data points. All of these comparisons were significant at the $p<0.05$ level before correction for multiple comparisons but were not significant after correction for multiple comparisons. Figure S2: RAS components that did not show any significant differences in gene expression between normal and tumor tissues. Top panels describe $\mathrm{AT}_{1}$ receptor gene (AGTR1) expression, middle panels describe $\mathrm{AT}_{4}$ receptor gene (LNPEP) expression, and lower panels describe angiotensin-converting enzyme-2 gene (ACE2) expression. Left panels show pairing of samples with connecting lines. Right panels show mean, SEM, and individual data points. Figure S3: relative expression of angiotensinogen gene $(A G T)$, with different stages of CRC at time of biopsy. One-way ANOVA revealed a significant $\left(F_{6,105}=3.117, p=0.0075\right)$ effect of the stage on gene expression. ${ }^{* *}$ Post hoc Bonferroni test indicated that $A G T$ gene expression during stage $2 \mathrm{~B}$ was significantly less $(p<0.01)$ than those during stage 1 or stage 4. (Supplementary Materials)

\section{References}

[1] R. L. Siegel, K. D. Miller, A. Goding Sauer et al., "Colorectal cancer statistics, 2020," CA: A Cancer Journal for Clinicians, vol. 70, no. 3, pp. 145-164, 2020.

[2] Globocan, "International Agency for Research on Cancer, Worldwide Incidence of Colorectal Cancer," 2020, https:// gco.iarc.fr/today/data/factsheets/cancers/10_8_9Colorectum-fact-sheet.pdf.

[3] United States Centers for Disease Control and Prevention, "Leading Cancer Cases and Deaths, All Races/Ethnicities, Male and Female," 2017, https://gis.cdc.gov/cancer/USCS/ DataViz.html.

[4] C. A. Doubeni, J. M. Major, A. O. Laiyemo et al., "Contribution of behavioral risk factors and obesity to socioeconomic differences in colorectal cancer incidence," JNCI Journal of the National Cancer Institute, vol. 104, no. 18, pp. 13531362, 2012. 
[5] R. B. Issaka and M. Somsouk, "Colorectal cancer screening and prevention in the COVID-19 era," JAMA Health Forum, vol. 1, no. 5, pp. e200588-e200588, 2020.

[6] L. Hamzehzadeh, M. Yousefi, and S.-H. Ghaffari, "Colorectal cancer screening: a comprehensive review to recent noninvasive methods," International Journal of HematologyOncology and Stem Cell Research, vol. 11, no. 3, pp. 250261, 2017.

[7] A. Israel, F. M. A. Correa, M. Niwa, and J. M. Saavedra, "Quantitative determination of angiotensin II binding sites in rat brain and pituitary gland by autoradiography," Brain Research, vol. 322, no. 2, pp. 341-345, 1984.

[8] M. S. Cappell, "Pathophysiology, clinical presentation, and management of colon cancer," Gastroenterology Clinics of North America, vol. 37, pp. 1-24, 2008.

[9] H. Takahashi, I. Iyoda, K. Takeda et al., "Centrally-induced vasopressor responses to sodium-potassium adenosine triphosphatase inhibitor, ouabain, may be mediated via angiotensin II in the anteroventral third ventricle in the brain," Japanese Circulation Journal, vol. 48, no. 11, pp. 1243-1250, 1984.

[10] K. el Bairi, K. Tariq, I. Himri et al., "Decoding colorectal cancer epigenomics," Cancer Genetics, vol. 220, pp. 49-76, 2018.

[11] M. G. Lubner, C. O. Menias, R. J. Johnson, A. H. Gaballah, A. Shaaban, and K. M. Elsayes, "Villous gastrointestinal tumors: multimodality imaging with histopathologic correlation,” Radiographics, vol. 38, no. 5, pp. 1370-1384, 2018.

[12] S. Sarvepalli, C. A. Burke, M. Monachese et al., "Natural history of colonic polyposis in young patients with familial adenomatous polyposis," Gastrointestinal Endoscopy, vol. 88, no. 4, pp. 726-733, 2018.

[13] F. C. Da Silva, P. Wernhoff, C. Dominguez-Barrera, and M. Dominguez-Valentin, "Update on hereditary colorectal cancer," Anticancer Research, vol. 36, no. 9, pp. 4399-4406, 2016.

[14] V. V. Lao and W. M. Grady, "Epigenetics and colorectal cancer," Nature Reviews Gastroenterology \& Hepatology, vol. 8, no. 12, pp. 686-700, 2011.

[15] J. H. Neo, E. I. Ager, P. W. Angus, J. Zhu, C. B. Herath, and C. Christophi, "Changes in the renin angiotensin system during the development of colorectal cancer liver metastases," BMC Cancer, vol. 10, no. 1, pp. 134-134, 2010.

[16] X. Zheng, G. Liu, G. Cui, M. Cheng, N. Zhang, and S. Hu, "Angiotensin-converting enzyme gene deletion polymorphism is associated with lymph node metastasis in colorectal cancer patients in a Chinese population," Medical Science Monitor, vol. 23, pp. 4926-4931, 2017.

[17] G. A. Makar, J. H. Holmes, and Y.-X. Yang, "Angiotensinconverting enzyme inhibitor therapy and colorectal cancer risk," JNCI: Journal of the National Cancer Institute, vol. 106, no. 2, 2014.

[18] R. Kedika, M. Patel, H. N. Pena Sahdala, A. Mahgoub, D. Cipher, and A. A. Siddiqui, "Long-term use of angiotensin converting enzyme inhibitors is associated with decreased incidence of advanced adenomatous colon polyps," Journal of Clinical Gastroenterology, vol. 45, no. 2, pp. e12-e16, 2011.

[19] E. B. Bruce and A. D. de Kloet, "The intricacies of the reninangiotensin-system in metabolic regulation," Physiology \& Behavior, vol. 178, pp. 157-165, 2017.

[20] A. C. Simões e Silva, A. S. Miranda, N. P. Rocha, and A. L. Teixeira, "Renin angiotensin system in liver diseases: friend or foe?," World Journal of Gastroenterology, vol. 23, no. 19, pp. 3396-3406, 2017.

[21] M. J. Giese and R. C. Speth, "The ocular renin-angiotensin system: A therapeutic target for the treatment of ocular disease," Pharmacology \& Therapeutics, vol. 142, no. 1, pp. 1132, 2014.

[22] R. A. S. Santos, A. J. Ferreira, T. Verano-Braga, and M. Bader, "Angiotensin-converting enzyme 2, angiotensin-(1-7) and Mas: new players of the renin-angiotensin system," Journal of Endocrinology, vol. 216, no. 2, pp. R1-17, 2013.

[23] J. L. Lavoie and C. D. Sigmund, "Minireview: overview of the renin-angiotensin system-an endocrine and paracrine system," Endocrinology, vol. 144, no. 6, pp. 2179-2183, 2003.

[24] R. M. Touyz, "Reactive oxygen species and angiotensin II signaling in vascular cells: implications in cardiovascular disease," Brazilian Journal of Medical and Biological Research, vol. 37, no. 8, pp. 1263-1273, 2004.

[25] G. M. Etelvino, A. A. B. Peluso, and R. A. S. Santos, "New components of the renin-angiotensin system: alamandine and the Mas-related G protein-coupled receptor D," Current Hypertension Reports, vol. 16, no. 6, pp. 433-433, 2014.

[26] A. Perdomo-Pantoja, S. I. Mejía-Pérez, L. Gómez-FloresRamos et al., "Renin angiotensin system and its role in biomarkers and treatment in gliomas," Journal of Neuro-Oncology, vol. 138, no. 1, pp. 1-15, 2018.

[27] L. Zhou, Y. Luo, S. Sato et al., "Role of two types of angiotensin II receptors in colorectal carcinoma progression," Pathobiology, vol. 81, no. 4, pp. 169-175, 2014.

[28] B. Goldstein, M. Trivedi, and R. C. Speth, "Alterations in gene expression of components of the renin-angiotensin system and its related enzymes in lung cancer," Lung Cancer International, vol. 2017, 8 pages, 2017.

[29] A. J. George, W. G. Thomas, and R. D. Hannan, "The reninangiotensin system and cancer: old dog, new tricks," Nature Reviews Cancer, vol. 10, no. 11, pp. 745-759, 2010.

[30] M. A. Sparks, S. D. Crowley, S. B. Gurley, M. Mirotsou, and T. M. Coffman, Classical renin-angiotensin system in kidney physiology, John Wiley \& Sons, Inc., Hoboken, NJ, USA, 2014.

[31] Q. Xu, D. D. Jensen, H. Peng, and Y. Feng, "The critical role of the central nervous system (pro)renin receptor in regulating systemic blood pressure," Pharmacology \& Therapeutics, vol. 164, pp. 126-134, 2016.

[32] K. G. Pringle, M. A. Tadros, R. J. Callister, and E. R. Lumbers, "The expression and localization of the human placental prorenin/renin- angiotensin system throughout pregnancy: roles in trophoblast invasion and angiogenesis?," Placenta, vol. 32, no. 12, pp. 956-962, 2011.

[33] J. J. Kang, I.. Toma, A. Sipos, E. J. Meer, S. L. Vargas, and J.. Peti-Peterdi, "The collecting duct is the major source of prorenin in diabetes," Hypertension, vol. 51, no. 6, pp. 1597-1604, 2008.

[34] G. Nguyen, F. Delarue, C. Burcklé, L. Bouzhir, T. Giller, and J. D. Sraer, "Pivotal role of the renin/prorenin receptor in angiotensin II production and cellular responses to renin," Journal of Clinical Investigation, vol. 109, no. 11, pp. 14171427, 2002.

[35] A. H. Danser, "Prorenin," Hypertension, vol. 47, no. 5, pp. 824-826, 2006.

[36] J. A. Luetscher, F. B. Kraemer, D. M. Wilson, H. C. Schwartz, and M. Bryer-Ash, "Increased plasma inactive renin in 
diabetes mellitus," New England Journal of Medicine, vol. 312, no. 22, pp. 1412-1417, 1985.

[37] G. Nguyen, "Renin, (pro)renin and receptor: an update," Clinical Science, vol. 120, no. 5, pp. 169-178, 2011.

[38] T. A. Stewart, J. A. Weare, and E. G. Erdos, "Human peptidyl dipeptidase (converting enzyme, kininase II), in methods in enzymology, Vol.80: enzymes involved in blood pressure regulation," Academic Press, 1981.

[39] J. N. Lorenz, "Chymase: the other ACE?," American Journal of Physiology-Renal Physiology, vol. 298, no. 1, pp. F35-F36, 2010.

[40] G. H. Caughey, "Mast cell tryptases and chymases in inflammation and host defense," Immunological Reviews, vol. 217, no. 1, pp. 141-154, 2007.

[41] E. A. McPherson, Z. Luo, R. A. Brown et al., "Chymase-like angiotensin II-generating activity in end-stage human autosomal dominant polycystic kidney disease," Journal of the American Society of Nephrology, vol. 15, no. 2, pp. 493-500, 2004.

[42] S. Park, B. J. Bivona, H. Kobori et al., "Major role for ACEindependent intrarenal ANG II formation in type II diabetes," American Journal of Physiology-Renal Physiology, vol. 298, no. 1, pp. F37-F48, 2010.

[43] S. R. Tipnis, N. M. Hooper, R. Hyde, E. Karran, G. Christie, and A. J. Turner, "A human homolog of angiotensinconverting enzyme:," Journal of Biological Chemistry, vol. 275, no. 43, pp. 33238-33243, 2000.

[44] M. Donoghue, F. Hsieh, E. Baronas et al., "A novel angiotensin-converting enzyme-related carboxypeptidase (ACE2) converts angiotensin I to angiotensin 1-9," Circulation Research, vol. 87, no. 5, pp. E1-E9, 2000.

[45] W. Li, M. J. Moore, N. Vasilieva et al., “Angiotensin-converting enzyme 2 is a functional receptor for the SARS coronavirus," Nature, vol. 426, no. 6965, pp. 450-454, 2003.

[46] P. Zhou, X. L. Yang, X. G. Wang et al., "A pneumonia outbreak associated with a new coronavirus of probable bat origin," Nature, vol. 579, no. 7798, pp. 270-273, 2020.

[47] T. Kakimoto, G. Oshima, H. S. J. Yeh, and E. G. Erdös, "Purification of lysosomal prolylcarboxypeptidase angiotensinase C," Biochimica et Biophysica Acta, vol. 302, no. 1, pp. 178182, 1973.

[48] R. C. Speth and M. Giese, "Update on the renin-angiotensin system," Journal of Pharmacology and Clinical Toxicology, vol. 1, no. 1, article 1004, 2013.

[49] J. Ma, H. Lyu, J. Huang, and B. Liu, "Targeting of erbB3 receptor to overcome resistance in cancer treatment," Molecular Cancer, vol. 13, no. 1, p. 105, 2014.

[50] S. Miura, S. Imaizumi, and K. Saku, "Recent progress in molecular mechanisms of angiotensin II type 1 and 2 receptors," Current Pharmaceutical Design, vol. 19, no. 17, pp. 2981-2987, 2013.

[51] R. C. Speth and K. H. Kim, "Discrimination of two angiotensin II receptor subtypes with a selective agonist analogue of angiotensin II, p-aminophenylalanine ${ }^{6}$ angiotensin II," Biochemical and Biophysical Research Communications, vol. 169, no. 3, pp. 997-1006, 1990.

[52] Y. Kambayashi, S. Bardhan, K. Takahashi et al., "Molecular cloning of a novel angiotensin II receptor isoform involved in phosphotyrosine phosphatase inhibition.," Journal of Biological Chemistry, vol. 268, no. 33, pp. 24543-24546, 1993.
[53] M. Nakajima, H. G. Hutchinson, M. Fujinaga et al., "The angiotensin II type 2 (AT2) receptor antagonizes the growth effects of the AT1 receptor: gain-of-function study using gene transfer," Proceedings of the National Academy of Sciences, vol. 92, no. 23, pp. 10663-10667, 1995.

[54] J. Kang, C. Sumners, and P. Posner, “Angiotensin II type 2 receptor-modulated changes in potassium currents in cultured neurons," American Journal of Physiology, vol. 265, no. 3, pp. C607-C616, 1993.

[55] M. A. Millan, D. M. Jacobowitz, K. J. Catt, and G. Aguilera, "Distribution of angiotensin II receptors in the brain of nonhuman primates," Peptides, vol. 11, no. 2, pp. 243-253, 1990.

[56] E. F. Grady, L. A. Sechi, C. A. Griffin, M. Schambelan, and J. E. Kalinyak, "Expression of AT2 receptors in the developing rat fetus," Journal of Clinical Investigation, vol. 88, no. 3, pp. 921-933, 1991.

[57] A. G. Pucell, J. C. Hodges, I. Sen, F. M. Bumpus, and A. Husain, "Biochemical properties of the ovarian granulosa cell type 2-angiotensin II receptor*," Endocrinology, vol. 128, no. 4, pp. 1947-1959, 1991.

[58] Y. Zou, H. Akazawa, Y. Qin et al., "Mechanical stress activates angiotensin II type 1 receptor without the involvement of angiotensin II," Nature Cell Biology, vol. 6, no. 6, pp. 499506, 2004.

[59] R. A. S. Santos, A. C. S. e Silva, C. Maric et al., "Angiotensin$(1-7)$ is an endogenous ligand for the G protein-coupled receptor Mas," Proceedings of the National Academy of Sciences, vol. 100, no. 14, pp. 8258-8263, 2003.

[60] Y. Luo, E. Tanabe, M. Kitayoshi et al., "Expression of MAS1 in breast cancer," Cancer Science, vol. 106, no. 9, pp. 12401248, 2015.

[61] K. L. Cook, L. J. Metheny-Barlow, E. A. Tallant, and P. E. Gallagher, "Angiotensin-(1-7) reduces fibrosis in orthotopic breast tumors," Cancer Research, vol. 70, no. 21, pp. 83198328, 2010.

[62] M. Troyanovskaya, G. Jayaraman, L. Song, and D. P. Healy, "Aminopeptidase-A. I. CDNA cloning and expression and localization in rat tissues," American Journal of Physiology Regulatory, Integrative and Comparative Physiology, vol. 278, no. 2, pp. R413-R424, 2000.

[63] M. de Gasparo, K. J. Catt, T. Inagami, J. W. Wright, and T. Unger, "International union of pharmacology. XXIII. The angiotensin II receptors," Pharmacological Reviews, vol. 52, no. 3, pp. 415-472, 2000.

[64] C. Llorens-Cortes and R. M. Touyz, "Evolution of a new class of antihypertensive drugs: targeting the brain reninangiotensin system," Hypertension, vol. 75, no. 1, pp. 6-15, 2020.

[65] S. Zini, M. C. Fournie-Zaluski, E. Chauvel, B. P. Roques, P. Corvol, and C. Llorens-Cortes, "Identification of metabolic pathways of brain angiotensin II and III using specific aminopeptidase inhibitors: predominant role of angiotensin III in the control of vasopressin release," Proceedings of the National Academy of Sciences, vol. 93, no. 21, pp. 1196811973, 1996.

[66] R. J. Kokje, W. L. Wilson, T. E. Brown, V. T. Karamyan, J. W. Wright, and R. C. Speth, "Central pressor actions of aminopeptidase-resistant angiotensin II analogs: challenging the angiotensin III hypothesis," Hypertension, vol. 49, no. 6, pp. 1328-1335, 2007. 
[67] Y. Luan and W. Xu, "The structure and main functions of aminopeptidase N," Current Medicinal Chemistry, vol. 14, no. 6, pp. 639-647, 2007.

[68] M. Letko, A. Marzi, and V. Munster, "Functional assessment of cell entry and receptor usage for SARS-CoV-2 and other lineage B betacoronaviruses," Nature Microbiology, vol. 5, no. 4, pp. 562-569, 2020.

[69] M. Zahn-Zabal, P.-A. Michel, A. Gateau et al., "The neXtProt knowledgebase in 2020: data, tools and usability improvements," Nucleic Acids Research, vol. 48, no. D1, pp. D328D334, 2019.

[70] S. R. Keller, H. M. Scott, C. C. Mastick, R. Aebersold, and G. E. Lienhard, "Cloning and characterization of a novel insulin-regulated membrane aminopeptidase from Glut4 vesicles (*)," Journal of Biological Chemistry, vol. 270, no. 40, pp. 23612-23618, 1995.

[71] A. L. Albiston, S. G. McDowall, D. Matsacos et al., "Evidence that the angiotensin IV $\left(\mathrm{AT}_{4}\right)$ receptor is the enzyme insulinregulated aminopeptidase $*$," Journal of Biological Chemistry, vol. 276, no. 52, pp. 48623-48626, 2001.

[72] J. W. Wright and J. W. Harding, "Contributions by the brain renin-angiotensin system to memory, cognition, and Alzheimer's disease," Journal of Alzheimer's Disease, vol. 67, no. 2, pp. 469-480, 2019.

[73] B. J. Yamamoto, P. D. Elias, J. A. Masino et al., "The angiotensin IV analog Nle-Tyr-Leu-psi-(CH2-NH2)3-4-His-Pro-Phe (norleual) can act as a hepatocyte growth factor/c-Met inhibitor," Journal of Pharmacology and Experimental Therapeutics, vol. 333, no. 1, pp. 161-173, 2010.

[74] F. Gembardt, S. Grajewski, M. Vahl, H. P. Schultheiss, and T. Walther, "Angiotensin metabolites can stimulate receptors of the Mas-related genes family," Molecular and Cellular Biochemistry, vol. 319, no. 1-2, pp. 115-123, 2008.

[75] V. T. Karamyan and R. C. Speth, "Enzymatic pathways of the brain renin-angiotensin system: unsolved problems and continuing challenges," Regulatory Peptides, vol. 143, no. 1-3, pp. 15-27, 2007.

[76] A. J. Turner, R. E. Isaac, and D. Coates, "The neprilysin (NEP) family of zinc metalloendopeptidases: genomics and function," BioEssays, vol. 23, no. 3, pp. 261-269, 2001.

[77] C. Bavishi, F. H. Messerli, B. Kadosh, L. M. Ruilope, and K. Kario, "Role of neprilysin inhibitor combinations in hypertension: insights from hypertension and heart failure trials," European Heart Journal, vol. 36, no. 30, pp. 19671973, 2015.

[78] U. Tisljar, "Thimet oligopeptidase-a review of a thiol dependent metallo-endopeptidase also known as Pz-peptidase endopeptidase 24.15 and endo-oligopeptidase," Biological Chemistry Hoppe-Seyler, vol. 374, pp. 91-100, 1993.

[79] C. N. Shrimpton, A. I. Smith, and R. A. Lew, "Soluble metalloendopeptidases and neuroendocrine signaling," Endocrine Reviews, vol. 23, no. 5, pp. 647-664, 2002.

[80] N. J. Wangler, K. L. Santos, I. Schadock et al., "Identification of membrane-bound variant of metalloendopeptidase neurolysin (EC 3.4.24.16) as the non-AT1, non-AT2 angiotensin binding site," Journal of Biological Chemistry, vol. 287, no. 1, pp. 114-122, 2012.

[81] M. Rashid, N. J. Wangler, L. Yang et al., "Functional upregulation of endopeptidase neurolysin during post-acute and early recovery phases of experimental stroke in mouse brain," Journal of Neurochemistry, vol. 129, no. 1, pp. 179189, 2014.

[82] J. A. García-Horsman, P. T. Männistö, and J. I. Venäläinen, "On the role of prolyl oligopeptidase in health and disease," Neuropeptides, vol. 41, no. 1, pp. 1-24, 2007.

[83] S. Tsukamoto, T. Ishikawa, S. Iida et al., "Clinical significance of osteoprotegerin expression in human colorectal cancer," Clinical Cancer Research, vol. 17, no. 8, pp. 2444-2450, 2011.

[84] C. J. Creighton, A. M. Hilger, S. Murthy, J. M. Rae, A. M. Chinnaiyan, and D. el-Ashry, "Activation of mitogenactivated protein kinase in estrogen receptor $\alpha$-positive breast cancer cells in vitro induces an in vivo molecular phenotype of estrogen receptor $\alpha$-negative human breast tumors," Cancer Research, vol. 66, no. 7, pp. 3903-3911, 2006.

[85] P. Ekambaram, J.-Y. L. Lee, N. E. Hubel et al., "The CARMA3-Bcl10-MALT1 signalosome drives NF $\kappa$ B activation and promotes aggressiveness in angiotensin II receptor-positive breast cancer," Cancer Research, vol. 78, no. 5, pp. 1225-1240, 2018.

[86] R. S. Coulson, S. H. Liew, A. A. Connelly et al., "The angiotensin receptor blocker, Losartan, inhibits mammary tumor development and progression to invasive carcinoma," Cancer Research, vol. 76, pp. 18640-18656, 2016.

[87] E. Oh, J. Y. Kim, Y. Cho et al., "Overexpression of angiotensin II type 1 receptor in breast cancer cells induces epithelialmesenchymal transition and promotes tumor growth and angiogenesis," Biochimica et Biophysica Acta - Molecular Cell Research, vol. 1863, no. 6, pp. 1071-1081, 2016.

[88] M. T. Wei, N. Chen, Y. Z. He et al., “Angiotensin-converting enzyme insertion/deletion polymorphism and gastric cancer: a systematic review and meta-analysis," Clinics and Research in Hepatology and Gastroenterology, vol. 39, no. 1, pp. 136144, 2015.

[89] N. Wang, D. F. Yang, B. Ji, and J. Y. Li, “Angiotensin-converting enzyme insertion/deletion gene polymorphism and lung cancer risk: a meta-analysis," Journal of the ReninAngiotensin-Aldosterone System, vol. 16, no. 1, pp. 189-194, 2015.

[90] C. Liu, H. Cui, D. Gu et al., "Genetic polymorphisms and lung cancer risk: evidence from meta-analyses and genome-wide association studies," Lung Cancer, vol. 113, pp. 18-29, 2017.

[91] K. Domińska, P. Okła, K. Kowalska et al., “Angiotensin 1-7 modulates molecular and cellular processes central to the pathogenesis of prostate cancer," Scientific Reports, vol. 8, no. 1, p. 15772, 2018.

[92] K. Zhang, D. Cheng, L. Yi, H. Shi, and G. Zhen, “Association between angiotensin I-converting enzyme gene polymorphism and susceptibility to cancer- a meta analysis," International Journal of Clinical and Experimental Pathology, vol. 7, no. 9, pp. 6291-6300, 2014.

[93] H. Lu, C. Wu, D. A. Howatt et al., "Angiotensinogen exerts effects independent of angiotensin II," Arteriosclerosis, Thrombosis, and Vascular Biology, vol. 36, no. 2, pp. 256265, 2016.

[94] J. Rein and M. Bader, "Renin-angiotensin system in diabetes," Protein and Peptide Letters, vol. 24, no. 9, pp. 833-840, 2017.

[95] G. W. Booz and K. M. Baker, "Molecular signalling mechanisms controlling growth and function of cardiac fibroblasts," Cardiovascular Research, vol. 30, no. 4, pp. 537-543, 1995. 
[96] T. Dierssen-Sotos, I. Gómez-Acebo, C. Palazuelos et al., "Relationship between drugs affecting the renin-angiotensin system and colorectal cancer: the MCC-Spain study," Preventive Medicine, vol. 99, pp. 178-184, 2017.

[97] J. Gao, Y. Marc, X. Iturrioz, V. Leroux, F. Balavoine, and C. Llorens-Cortes, "A new strategy for treating hypertension by blocking the activity of the brain renin-angiotensin system with aminopeptidase A inhibitors," Clinical Science, vol. 127, no. 3, pp. 135-148, 2014.

[98] J. W. Harding and D. Felix, "Angiotensin-sensitive neurons in the rat paraventricular nucleus: relative potencies of angiotensin II and angiotensin III," Brain Research, vol. 410, no. 1, pp. 130-134, 1987.

[99] Y. Namkung, C. LeGouill, S. Kumar et al., "Functional selectivity profiling of the angiotensin II type 1 receptor using pathway-wide BRET signaling sensors," Science Signaling, vol. 11, no. 559, article eaat1631, 2018.

[100] D. M. Boudreau, E. Koehler, S. J. Rulyak, S. Haneuse, R. Harrison, and M. T. Mandelson, "Cardiovascular medication use and risk for colorectal cancer," Cancer Epidemiology Biomarkers and Prevention, vol. 17, no. 11, pp. 3076-3080, 2008.

[101] S. Bangalore, S. Kumar, S. E. Kjeldsen et al., "Antihypertensive drugs and risk of cancer: network meta-analyses and trial sequential analyses of 324168 participants from randomised trials," The Lancet Oncology, vol. 12, no. 1, pp. 65-82, 2011.

[102] S. Misra and J. J. Stevermer, "ACE inhibitors and ARBs: one or the other-not both-for high-risk patients," The Journal of Family Practice, vol. 58, no. 1, pp. 24-27, 2009.

[103] B. M. Mearns, "Hypertension: new meta-analysis shows no cancer risk with angiotensin-receptor blockers," Nature Reviews Cardiology, vol. 8, no. 5, p. 243, 2011.

[104] T. Datzmann, S. Fuchs, D. Andree, B. Hohenstein, J. Schmitt, and C. Schindler, "Systematic review and meta-analysis of randomised controlled clinical trial evidence refutes relationship between pharmacotherapy with angiotensin- receptor blockers and an increased risk of cancer," European Journal of Internal Medicine, vol. 64, pp. 1-9, 2019.

[105] L. Cao, S. Zhang, C. M. Jia et al., “Antihypertensive drugs use and the risk of prostate cancer: a meta-analysis of 21 observational studies," BMC Urology, vol. 18, no. 1, p. 17, 2018.

[106] ARB Trialists Collaboration, "Effects of telmisartan, irbesartan, valsartan, candesartan, and losartan on cancers in 15 trials enrolling 138,769 individuals," Journal of Hypertension, vol. 29, no. 4, pp. 623-635, 2011.

[107] C. Röcken, K. Neumann, S. Carl-McGrath et al., “The gene polymorphism of the angiotensin I-converting enzyme correlates with tumor size and patient survival in colorectal cancer patients," Neoplasia, vol. 9, no. 9, pp. 716-722, 2007.

[108] R. Ruiter, L. E. Visser, C. M. Van Duijn, and B. H. C. Stricker, "The ACE insertion/deletion polymorphism and risk of cancer, a review and meta-analysis of the literature," Current Cancer Drug Targets, vol. 11, no. 4, pp. 421-430, 2011.

[109] D. Mansouri, D. C. McMillan, C. S. D. Roxburgh, E. M. Crighton, and P. G. Horgan, "The impact of aspirin, statins and ACE-inhibitors on the presentation of colorectal neopla- sia in a colorectal cancer screening programme," British Journal of Cancer, vol. 109, no. 1, pp. 249-256, 2013.

[110] D. Mishra, S. Singh, and G. Narayan, "Role of B cell development marker CD10 in cancer progression and prognosis," Molecular Biology International, vol. 2016, Article ID 4328697, 9 pages, 2016.

[111] D. G. Passos-Silva, E. Brandan, and R. A. S. Santos, "Angiotensins as therapeutic targets beyond heart disease," Trends in Pharmacological Sciences, vol. 36, no. 5, pp. 310-320, 2015.

[112] T. Shimomoto, H. Ohmori, Y. Luo et al., "Diabetes-associated angiotensin activation enhances liver metastasis of colon cancer," Clinical \& Experimental Metastasis, vol. 29, no. 8, pp. 915-925, 2012.

[113] H. M. Stephen, R. J. Khoury, P. R. Majmudar et al., "Epigenetic suppression of neprilysin regulates breast cancer invasion," Oncogene, vol. 5, no. 3, article e207, 2016. 